\title{
Challenges for Insurers in the Nineties
}

\author{
by Henning Schulte-Noelle*
}

\section{Changing customer needs}

More than 2000 years ago Heraclit coined the saying: "Everything moves". For an observer of the economic activity of mankind, it is thus comforting to realize that a changing environment is just another aspect of life as we know it.

As managers of insurance companies, we cannot assume the role of the idle bystander. Our customers expect us to adjust to changing markets, to fulfill our obligations under the contracts we sell. Our shareholders expect us to do even better, namely provide an adequate return on their investment. While there are some problems which are specific to particular companies, there are also many issues which all insurers have to face. A few of them shall be addressed in this paper.

For an insurer, as for any company, it is vital to know to the best possible extent what the customer wants. If there is a widening gap between the customer's demands and the insurer's supply of adequate products, the insurer runs the risk of losing business. Any insurer who closely follows the needs of his clients will have noticed that they have altered considerably over the past years and that the pace is accelerating. These changes are of a very different nature. Before analyzing in more detail the causes of these changes, though, three general hypotheses which characterize today's insurance customer will be set forth:

Today's clients' insurance needs are more differentiated than in the past. There is less homogeneity of risk exposure and risk perception among clients.

The number of insurance clients is constantly growing due to the emergence of new risks and the increasing need for securing and safeguarding all aspects of life.

Customers are becoming better informed about how to manage risks and about the intricacies of different insurance products.

What does that mean for the insurer who wants to keep his customers content and satisfy their insurance needs? In order to serve the client and keep his loyalty, the insurer has to develop new and creative approaches. He has to provide better service as well as enhanced value to the customer. This, of course, has repercussions on the overall strategy of the insurance company, on its organizatioal structure, on the personnel and on the technologies applied by the insurer. These will be dealt with in more detail in the course of this paper.

* Chairman of the Executive Board, Allianz AG Holding, Munich. Paper presented at the 30th Annual Seminar of the International Insurance Society, Madrid, June 19-23, 1994. 


\subsection{The aging society}

While there are few trends which can be forecast with confidence over the next few decades, there is one prediction that can safely be made about the countries of western Europe. Their populations will grow much older over the next 40 years. In the 18 western European member states of the OECD, the number of people aged 65 and over will rise from $50 \mathrm{~m}$ to more $70 \mathrm{~m}$ between 1990 and 2030 . During the same period the number of people of working age will fall.

Similar trends can be seen in other leading world economies, such as the US and Japan. The populations of the newly industrialized countries of the Pacific Rim, such as Singapore and Taiwan, are also aging rapidly. But countries on the brink of development, such as China, India or Brazil, will have a much lower share of elderly people in their populations over the next 40 years.

There are two principal forces of demographic change in western Europe: improved medical care connected with better living conditions and a lower birth rate.

First of all, medicine has made a lot of progress towards extending the individual's life expectancy. The war against the majority of the most threatening diseases has been won. Preventive health examinations help to reduce the danger of a heart attack or cancer. Certain inherited diseases have been attributed to particular genetic dispositions that now can be diagnosed a long time before they break out. For most major diseases, with the exception of AIDS, there is an effective treatment available.

The second force of demographic change - the low birth rate - is partly a consequence of insurance. While more than 100 years ago, the parents depended on many children to ensure security in old age, the family network nowadays is replaced more and more by the state and the employer. In the 19th century in Germany, Bismarck introduced the state-funded retirement system which is still in force today. It provides retirees with benefits which have been funded by the working population. Thus, it was anonymous as opposed to the family network, but certainly much more flexible. But it depends on many young people of working age contributing to the state fund. However, this foundation is eroding fast, as there are many young couples who want one child only or none at all. This trend can be observed in Europe now. Taken together with the medical advances discussed above, it leads to a rather unbalanced age pyramid, with a very thin basis.

The above mentioned developments result in ever increasing health care costs and the growing importance of a distinct new consumer group, the elderly part of the population.

The rising health care costs pose the problem of how to fund them on the one hand and how to reduce them on the other hand. Both questions are highly political and are likely to provoke lengthy debates among all parties involved - the insurers, the insured, the government and the employers. As one can see from the lively discussions in the U.S., there is certainly no ready-made solution applicable for all of western Europe. Thus, observations here will be restricted to the options of the insurer.

In order to make medical care affordable for everybody, insurers must develop a broad range of well differentiated products which cater for the different income groups in society. They also will have to serve those clients who take out basic health cover insured by the state and wish to have additional or specific risks covered by a private insurer. 
They may wish to seriously consider so-called health maintenance organizations (HMOs). These HMOs closely combine the financing side and indemnity. As for the reduction of health care costs, insurers may exclude from their cover certain costly medical practices or restrict treatment by the more expensive doctors or clinics. But at the same time, in order to minimize claims, policy conditions may stipulate comprehensive preventive health examinations for the sake of both the customer and the insurer.

A specific aspect of medical care which combines the problem of high costs and old age is permanent care insurance. The introduction of permanent care insurance and its funding have sparked an ongoing debate in Germany, which only came to a close at the beginning of this year. The compromise which the major political parties agreed upon entails the following: from January 1995, a compulsory premium of 1 percent of the salary will be levied to finance permanent care insurance. Both the employer and the employee will each cover 50 percent of the premium. In order to make up for the employer's expenses, one public holiday is cut. This is only one possible solution to a question which will become more and more relevant to all aging societies.

The other major need of the elderly is financial security. State pensions, the so-called first column of retirement benefits, scarcely will suffice to sustain the former living standard, in particular due to the shrinking number of younger people paying into the state pension fund. The second column, employer-funded pension plans, was never more than a supplement to the other sources of income. Thus the third column, personal pension plans, will become increasingly important. This implies a great opportunity for the insurance industry. Again, new products will have to be developed, products that complement traditional pension schemes and adapt to changing needs during the client's life. This will force the insurer to create products which are much more flexible and more difficult to administer. In order to offer enhanced value to the client, the insurer may wish to combine permanent care insurance with retirement homes. This could be in the form of a financial shareholding only or could entail actively shaping the policy of this retirement home by choosing doctors and types of medical care available.

Another specific group of clients emerging from the changing age pyramid is the socalled generation of heirs. These younger and middle aged people will inherit the fortunes of their parents. The insurance industry has to cater to their specific needs as well, by offering products designed to minimize inheritance and capital taxes and secure personal wealth.

\subsection{New markets in Eastern Europe and Asia}

The changing age pyramid offers major opportunities and challenges to insurers. Another serious challenge is the fall of the iron curtain and the emergence of new markets in Eastern Europe. Just a few years ago the situation of the insurance industry in Eastern Europe was clear cut. In countries such as Hungary, Poland and the former Czechoslovakia there were insurance monopolies modelled on the Soviet insurers Gosstrakh and Ingosstrakh. One was in charge of domestic risks, the other was responsible for covering reinsurance and international (foreign currency) risks. There was no insurance market in the sense of various suppliers competing for the customer.

Today, as you know, a completely different picture presents itself to the Western insurer taking a look eastwards across the borders. Changing economies in the East hold 
considerable implications for all branches of industry, including insurance. During the relatively short period of four years, particularly Hungary, the Czech Republic and Poland have taken major steps towards a free market economy. To a great extent, they soon introduced new product lines. The small- and medium-sized commercial sectors are the predominant driving forces of change. So, for example, almost 50 percent of the Polish GDP already is produced by the private sector.

Foreign direct investment is another important reason for the obvious improvement in the former Comecon countries. The main investors come from the US, Germany, France and the United Kingdom. More than 80 percent of total direct investment originates from these four countries. These foreign investors require insurance cover of Western standards. At the same time, newly emerging industrial sectors require effective compensation in case of loss. Since the old state insurers cannot provide this cover nor the necessary financial security, there is a need for Western insurers to follow their clients abroad. This may take the form of co-operating with local companies, opening new offices or also acquiring local companies. It always will entail the transfer of technology and know-how.

What is the situation of the insurance industry nowadays in these countries? Individuals increasingly opt for insurance policies covering their personal belongings and securing their old age. In those countries where the local state monopoly insurers still exist, they are unable to adjust adequately to the changing needs of their customers because they lack financial strength and expertise. At the same time they have to improve their service because insurance is no longer considered by the customer as a tax but as a product. This provides opportunities for newcomers. Given their expertise and certain degree of flexibility, foreign insurers with a long-term strategic outlook can take advantage of the attractive opportunity to participate as active players in these markets.

Perhaps even more enticing for Western European insurers are the markets of the newly industrialized countries in East Asia and South East Asia. For example, South Korea already has a rather advanced industrial and insurance sector. In other countries, like India or Indonesia, rapid industrialization and increasing personal wealth, at least for parts of the population, open up new segments for the insurance industry. China is still in an early stage of its development, but its market has a huge potential for the next century. Direct investment of Western companies in this region is growing, and multinational customers require cover for their worldwide operations. So insurers have to adapt to the internationalization strategy of their clients. Thus, all major multinational insurers have built up some form of International Department to deal with the requirements of their international industrial clients.

\subsection{Rising crimes rates}

One rather worrying general trend most European countries currently are experiencing is the rise in crime rates which leads to increased claims ratios. Crime is on the rise due to a change in values caused by weakening social ties, economic hardship and less state support. The collapse of the political systems of the former socialist countries does not only have positive effects. For the insurers, the unexpectedly negative side effect is that criminal groups have mushroomed. The income differences between East and West, together with the open borders, have caused a significant increase both in casual and organized crime. Casual crime may be a passing phenomenon, but organized crime probably will remain a persistent concern for Western European insurers. Motor insurance in particular is severely 
affected. Many insurers were taken by surprise when vehicle thefts increased by more than 50 percent in some regions within one year. With around 600,000 registered car thefts in 1992, the United Kingdom takes the inglorious first place in Europe, followed by France, Italy and Germany. However, whereas in Britain two thirds of vehicles are recovered, in other European countries far fewer than one third ever are found again. In 1992 in Germany alone, organized vehicle theft caused the insurance industry losses of some DM 2.5 billion.

Insurers have to develop strategies to cope with this situation. One possibility is to raise premium rates and to react by enforcing stricter risk selection, although this does not directly correspond with the clients' needs. Measures taken so far to protect the customer from thefts are advice on theft protection for car or house. Another means is to work together with industry to develop truly effective built-in anti-theft devices for cars.

There is also an urgent need for more cooperation withing the international insurance community in fighting organized crime across borders. Such efforts can be even more effective if they are supported by the respective governments and their police forces. Thus, both the customer and the carrier can react to an increasing crime rate. The customer receives enhanced value by avoiding a claim in many cases.

\subsection{Increasing importance of liability insurance}

A stronger need for security arises not only from increasing criminality, but also from dangers connected with increasing pollution and new technologies. A growing concern for the environment is reflected in more rigorous liability provisions and in stricter court decisions that interpret and thereby modify the law.

Court awards for pollution and product liability are increasing. In many cases, they relate to problems we have inherited from the past, when the potential for damage and recourse through the courts had not yet been discovered. Goods had been (and sometimes still are) brought to market in the belief that they were safe and in compliance with all regulations. It then turned out that they were not safe and that they caused damage and injury. Asbestos is one of the best known of such products. In the same way, nature has been used as an inexhaustible dustbin with noxious fumes being released in the air, effluents dumped at seas or into lakes and unsafe products stored on land which have then contaminated underground water reserves. These pollutants then threaten or actually cause loss and suffering to entire populations. For both unsafe products and pollutants, injured parties have to be compensated and unsafe buildings and locations have to be cleaned up. Who pays? Who benefits?

So far, Europe has been fairly successful at avoiding the worst excesses of the American system which tends to make the entity with the deepest pocket pay for past misdemeanors and which rewards the lawyers handsomely in the process. In most European countries, old liabilities are treated differently from new ones. This means that the European insurance industry is able and willing to shoulder the new responsibilities and liabilities. There is, however, a trend whereby governments and courts tend to react to the problems of the past by putting the onus on present property owners and employers or past insurers. This trend is reflected in liability insurance where the concept of the duty of care is being constantly widened and deepened. European insurance companies are finding that the claims frequency is increasing. Reserves which were set up years ago are insufficient. The 
historic data on which insurance companies used to base their reserving methods has to be updated. In many cases, new methods have to be adopted.

Because of the very substantial amounts involved, these changes will have a considerable impact on our lives. Industry with high pollution tends to move to countries which are less pollution conscious, thereby causing job losses in developed countries and endangering the health of the populations of developing countries. As was just pointed out, the cost of boosting reserves for past misdeeds has to be borne by present and future policyholders and shareholders.

In the past, when issuing environmental liability cover, many insurers made the expensive mistake of greatly underestimating the scope of the claims they would have to face in the future. In order to avoid this, insurers have to turn away from a wholesale coverage of environmental risks in favor of careful risk selection. Engineers acting on behalf of the insurer will have to pay regular visits to the facilities that have been identified as especially dangerous. In view of the particular nature of liability insurance, we need to take into account any impairments in the vicinity of the insured plant. Is the plant located in an industrial or a residential neighborhood? Are there schools or kindergartens close by? What are the local meteorological, geological and hydrogeological conditions? These, among many others, are important aspects which have to be clarified before issuing the policy.

For the customer, this is of considerable benefit, too. Qualified specialists regularly provide the client with essential information about his or her premises. This is of vital interest in times when safety deficiencies can lead to closure of the plants by the authorities and also to the personal criminal liability of the management, not to mention the loss of prestige that the policyholder suffers when deficient safety is associated with damage to the health of his customers. We therefore trust that the insured will confide in us and cooperate by fully disclosing all the risks inherent in the facility to be insured.

\subsection{Natural and man-made catastrophes}

When we speak about natural hazards, it is important to distinguish between two different groups in principle :

- single, "pure" natural hazards like earthquakes, floods, volcanic eruptions, spring tides and hurricanes

- "man made" or at least "man induced" catastrophes like oil spills and chemical or nuclear catastrophes.

Natural catastrophes, such as hurricanes, floods, tornadoes, earthquakes or volcanic eruptions, are reported in the media with considerable regularity. The increasing severity and intensity of such catastrophes throughout the last two decades is terrifying, not to mention the human toll and the hardship suffered by the victims. The insurance industry worldwide is the sector of the economy which primarily suffers from this phenomenon since the number of reported claims and the sums involved have increased in all regions of the world.

In 1992 alone, the total economic damage due to natural hazards was more than US \$ $60 \mathrm{bn}$, of which some US $\$ 25$ bn are expected to be insurance claims. For 1993, insured claims amount to US $\$ 10 \mathrm{bn}$, while total economic damage was five times as high (source: Munich Re).

America suffered 75 percent of the economic damage worldwide. The major causes of the economic damage were windstorms. 1992 was no exceptional year and continues a trend 
which can be observed all through the 1980 s. While "man made" natural hazards at least seem to be more easily controllable due to the human factor involved, most of the causes of purely natural catastrophes, such as the greenhouse effect, the increasing desertification and higher sea levels are out of our direct control.

What can insurers do to minimize this high risk potential for their clients? As a longer term measure, "risk management" is the key. The insurer, in close co-operation with the client, has to analyze all factors relating to the client's business to determine the risk exposure. This very individual approach includes the following main steps:

- Analysis of possible risk factors,

- Assessment of the probability that the loss will actually occur and

- Suggestion and pricing of alternative remedial action.

So, for example, insurers can advise their customers on building sky scrapers strong enough to withstand earthquakes of a certain intensity on the Richter scale. They also may advise them to avoid storing petrol in flood-prone areas.

Besides these more technical means, insurers can cope with their customers' growing demand for capacity by forming pools to divide risk among a number of carriers, thereby creating added capacity and guaranteeing the insurability of catastrophe damage.

\subsection{Technological challenges}

Besides man-made and natural hazards, technological progress has created risks of an ever increasing size. International construction projects such as the Channel Tunnel linking the United Kingdom with the European continent, the Great Belt bridge in Denmark or the new airport in Hong Kong require a consortium of insurers with special expertise and high capacity. These projects are of such a magnitude that they could not be undertaken at all if adequate insurance cover were unavailable. Their exposure is even too high for leading insurers to cover them on their own. Insurers participating in such risks have to develop special expertise by conducting research on the areas concerned.

Allianz, for instance, has founded a special research institute, the Allianz Centre for Technology, which is a service company with more than a hundred engineers providing technical expert reports, studies, tests, training and development. The goal of this institute is to make technology as safe as possible - safe for people and for the environment - and to make it insurable. The research activities range from investigation into corroded microchips to the total loss of a plant section or an entire plant. Generally, investigations are carried out in their laboratories on the bais of specimens from the loss site and an exact description of the circumstances of the loss. In certain cases the employees of the institute also are sent directly to the site of the incident. Other companies have funded similar projects.

Other risks resulting from technological developments are those connected with genetic engineering. While there are still strict regulations concerning the application of genetic research findings to human beings, in the food sector we are confronted with the first products created by genetic engineers. The consequences of these plants being grown next to "regular" plants and the long-term effects of consuming them are still unknown. The insurance industry is not yet sufficiently prepared to deal with these matters. But as the application of genetic engineering becomes more widespread, the need for adequate insurance cover will grow as well. It is the insurer's task to keep up with such developments. 


\subsection{Changes in market structure and competition}

As a representative of the European insurance industry, the author would like to focus on the changing market situation in Europe. Since 1986 several directives have been passed by the EU Commission to achieve harmonization, deregulation and liberalization of the various European insurance markets. In 1990 the commercial insurance segment was deregulated, and by July 1994 this also will be the case with personal insurance lines. The main feature of the reform is the cessation of more or less all product approval and also of authorization by the supervisory authority concerning terms and tariffs of foreign carriers in a host member state. In addition, the remaining material and financial supervision will be transferred exclusively to the supervisory authority in each insurer's country of incorporation.

These legislative initiatives are likely to result in increased competition with regard to price levels and the improvement of service to the customer. However they also imply that there is a high probability that the less efficient and weaker competitors will have to exit the market. The current number of more than 4,000 insurance companies operating in the EU will decline. The trend towards expansion by acquiring smaller insurers in other countries has been going on now for almost a decade. Most of the major players have already established themselves via subsidiaries or branches in many European markets. If they are well financed and managed, they can offer something which policyholders may find more and more important, i.e., financial security.

Since it also will be more difficult for the insured to fully understand the cover provided by an insurance product, customers are likely to turn to well trained financial intermediaries for advice. As a result, insurers will have to ensure - especially with more complicated products - that sales personnel is well trained. Being a rather invisible commodity, insurance requires a great deal of knowledge about the cultural, socio-economic and legal environment of each region. Deregulated markets in particular tend to experience increased emphasis on a relationship between customer and sales office which is based on personal trust and confidence.

At the same time, there is a tendency for regulatory bodies to make the financial intermediaries more responsible for the advice given. In order to provide "best advice", the intermediaries will have to seek closer cooperation with one or a few reliable insurers in order to obtain all the information needed about their products. Thus, we have to observe the apparent paradox that while the insurance markets are being deregulated and liberalized, there are obvious initiatives to regulate and monitor the profession of insurance intermediaries.

The EU Commission, for instance, published a recommendation in December 1991 including the following points :

- all insurance intermediaries must fulfill certain personal and professional minimum qualifications and

- a distinction has to be made between independent and tied intermediaries. The independent financial intermediaries are themselves liable, whereas the insurer is liable for the advice given to consumers by the tied agents who represent him.

Although this recommendation does not have to be enforced in the national laws of the EU Member States, it clearly shows the direction in which the regulatory bodies in our industry are moving. Two developments, which appear to incorporate contradictions, 
can be observed in the aftermath of the implementation of the EU guidelines. One is that while the insurer's market is deregulated, intermediaries have to undergo tighter control by the supervisory authority concerning not only financial solvency, but also the material aspects of insurance products. The other is that increased competition with the goal of benefitting consumers seems to result in a reduced number of insurers in the market.

Besides deregulation, there are also market forces which are putting pressure on traditional market structures. Direct writers are emerging, offering attractive conditions at a low price. Through the use of sophisticated new technologies, their cost advantage enables them to gain ground against established providers with traditional cost structures. Thus, other players in these market segments have to reduce their expense level as well in order to stay in the game.

\subsection{Responses to change}

As mentioned earlier, the changing environment forces insurance managers to react on various levels: products, technology and people. Some key factors for each of the above mentioned fields will now be highlighted.

A crucial step to gaining competitive advantage over other providers of financial services will be the improvement of the quality of service. New products and features will be developed in order to meet consumer needs. With the support of sophisticated computer software it will be possible to enter a new age of individualized risk cover according to the specific needs of each policyholder. Flexible and efficient risk selection with respect to typical target groups showing a similar risk pattern will permit a much more customer oriented marketing and rating.

As one example, in former times the enormous administrative costs used to prevent insurers from classifying policyholders according to detailed risk criteria, for instance, in motor insurance, the number of miles driven, sex, profession, quality and age of the vehicle, etc. The widespread use of modern computer software will enable us to be more specific in allocating higher premiums to consumer groups with a higher risk profile and vice versa.

By applying such sophisticated software, we gain the additional benefit that policyholders with a long-standing low risk profile can receive appropriate premium reductions. Parallel to the continuous improvements of computers, we will be able to include more and more risk selection criteria in our statistical analysis. The goal is to develop a modular product system which enables us to provide individualized risk cover to policyholders depending on their specific situation. Simultaneously, the insurer will be able to identify standardized risk factors causing claims. Thus, technological innovations will benefit not only policyholders - in the form of more individualized cover - but also insurers in the form of improved statistical evidence relating to risk factors.

On the operational level, insurance companies will differentiate between various service levels as well as try to cut costs.

New uses for existing technology include database marketing, customer-based policy administration systems, electronic links to agents and electronic publishing. Emerging technologies such as multifunction workstations, image processing and expert systems will contribute to the transformation of the future working environment of the insurance manager. This also will require increased emphasis on proper planning of investments in technology. 
In order to raise productivity across all categories of employees, training will gain in importance. The executive management of successful companies will recognize that change is here to stay and will reward and promote those who succeed in making change work by creatively implementing and realizing new ideas. If good performance is expected in a changing environment, then training is fundamental to success. More than in former times, life is a continuing process of learning because changes occur increasingly rapidly. Without a doubt, this list of major changes of customer needs is far from complete; and we will see more of them in the years ahead.

\section{Core business focus: Is it better to be multiline or niche?}

The customer is becoming more and more demanding, and competition in the market place is becoming ever fiercer. The insurance cycles are getting shorter and shorter, putting increasing pressure on insurers to adopt clear strategies. Confronted with upheavals in the market, suppliers have to ask themselves how best to respond, not only in order to meet the changing needs of the customer, but also in order to outperform the competition, from a shareholder's standpoint. It is becoming increasingly difficult for just one supplier to meet all the demands of his clients. These changing customer needs create opportunities to increase market share and generate extra profits. However, before answering the question of what is better, multiline or niche, let us first define the terms "multiline" and "niche" and look at the evidence from the last few years.

\section{I. Definition}

There are probably as many definitions of niche and multiline as there are delegates in this auditorium. Niche generally conjures up the image of a relatively small, well-defined market with unique characteristics either in terms of the target market segment, distribution method or product and service being offered. Multiline, on the other hand, gives a much wider, fruit salad impression of different lines of business which might or might not have common features. However, both definitions may fail to take account of the dynamics of the market and may not do justice to what companies are actually achieving. On the one hand, brand names enable a provider to target specific segments. On the other hand, developments in computer technology and computing power allow lines of business to be analyzed according to an infinity of underwriting criteria, enabling underwriters to target those areas where different lines of business overlap and are profitable. In both these examples, one could argue whether the approach is niche or multiline.

Having highlighted the difficulty of giving a rigid definition of niche and multiline, refuge will be sought in a more dynamic description which recognizes the continuing pressures on insurers to adapt to the needs of their clients and to respond to the pressures of the market.

A glance at competitors worldwide shows that they come in all shapes and sizes and that they have all adopted strategies to suit their own needs. The spectrum ranges from the Allfinanz or Bancassurance concepts to the niche player who concentrates on specific products, market segments or regions via a whole gamut of alliances and co-operations. The insurance carrier will range from the multinational insurer to the regional underwriter. There are also examples of large multinationals who are also niche players for parts of their business. The question of multiline or niche therefore has to be read in the context of allowing a company to play to its strengths and to fully utilize market opportunities. 
If the starting point for our question is how to define the strategic direction of an insurance company, we first need to find out how big it is, how much financial muscle it has, in which market segments it operates, how competitive these are and the advantages the company has over its competitors.

In regard to this analysis, insurance is no different from any other industry: companies have to concentrate on their core business; and even though there are endless permutations of the Allfinanz/Bancassurance concept, from multiline insurance to the regional specialized underwriter, insurers have to pick and mix the ingredients that suit them best.

\subsection{Advantages/disadvantages of multiline/niche}

Before looking at practical examples of some of the well-known strategies or concepts of horizontal integration, it is worth remembering some of the advantages and disadvantages of each strategy.

2.2.1. Multiline. In pursuing a multiline strategy, companies will seek to utilize their customer base by cross-selling products. The customer benefits by obtaining services from a trusted supplier. The company benefits by creating a stronger bond to the customer. A multiline strategy should also aim to give the company a better spread of risks, as a downturn in one market hopefully should be compensated by other markets. This should enable the company to withdraw from the unprofitable segments until market conditions improve. At the same time resources can be more profitably redirected to areas where demand is stronger. However, not every company can afford this approach. A multiline approach generally requires more capital, even though the larger and more diversified the insurance portfolio, the lower the risk and hence also the capital costs. Multiline also requires a wider spread of expertise. This in turn could lead to a splitting of resources and to some lines of business subsidizing others. The complications of realizing the synergies will sometimes outweigh the advantages. Indeed, one sees today that conglomerates are spinning off activities which had been acquired in the hope of achieving synergies.

Neither can a multiline approach be used as a refuge for mediocrity. Companies have to develop competitive advantage. Medium-sized companies risk falling into the trap of trying to overextend themselves when they do not have sufficient resources to underpin their ambitions. Such companies which lack a clearly defined strategy will be the losers in a more competitive market over the next few years. This was also the conclusion reached in a survey of 232 board members of Germany's 120 largest insurance companies in 1992 (source: Heidrick \& Struggles).

2.2.2. Niche. The niche approach allows a company to concentrate all its efforts on one segment. Conflicts of strategy with other segments do not arise and therefore the company stands or falls by its chosen strategy. For example, it could be very attractive to be a low cost producer, targeting exclusively civil servants. The chosen target segment, the consumer, benefits by having a company which caters to all the needs of that group.

Niche companies generally do not have and do not require substantial amounts of capital, and they therefore make virtue out of necessity. These companies then can build up their expertise and gain further advantages, thus increasing the entry price for competitors.

Aspects such as a superior level of expertise, cost advantages and more efficient distribution mean that niche players still will have certain opportunities, even in highly competi- 
tive markets. The downside, however, is that these niche companies are dependent on one line of business; and their survival can be threatened if regulations change or big companies suddenly target their niche. This is well illustrated by the UK life insurance market. The number of suppliers of life insurance, whether life companies, mutuals or life operations of composites, has declined. It is set to decline further as a number of walking wounded fall by the wayside. This fall is due to increased regulation and control of distribution by banks and building societies.

Another type of niche company is characterized by the form of its distribution channel. The number of direct writers has increased substantially. Initially these companies were small specialists with no broker links; and they were centralized, with low overheads and state of the art computer and telephone systems. They generally have aimed exclusively at the motor market which is compulsory and one of the most price sensitive. However, the initial capital outlay is heavy in terms of acquiring a stable customer base. Indeed, the fear was that by targeting the most price sensitive segment in the market, lapse rates would be high. This generally has been successfully counterbalanced by creaming off the best risks in the market and adopting a cherry picking underwriting and pricing strategy. In the UK some of these direct writing motor companies have been so successful that they are branching out into other markets, such as home contents. They have gained such a significant market share that they now have been joined by the composites who have adopted the attitude that if you can not beat them, join them.

Let us now turn to some of the factors influencing the choice of strategy.

\subsection{Factors influencing the choice of strategy}

2.3.1. Market pressures: Intensity of competition also influences the choice of multiline or niche. In good times, companies expand into new areas; newcomers enter the market focusing on the most profitable niches in an attempt to build a solid platform. If they are successful, they branch out. In bad times, the number of companies contracts through insolvencies, mergers and acquisitions. Companies retrench to their most profitable core business.

2.3.2. Size. Big companies tend to pursue a multiline strategy. A niche is unlikely to be sufficiently large to allow them to fully deploy their capital. On the other hand, even a big multinational company can be a successful insurance provider targeting certain regions or a focused market segment with limited products. This presupposes, however, that within the large company, smaller units are allowed to grow, which will have advantages over small, undercapitalized competitors through their belonging to a larger group.

Small companies, on the other hand, tend to concentrate on a niche as they generally suffer capital constraints. However, as market conditions change and competition intensifies, companies always will have to ask themselves in which areas their core strengths lie, where they have to prune back and where they successfully can graft their competitive advantages from one segment on to another.

Big insurance companies seek to attract customers who require all kinds of cover, so that an insurance company may meet its customers' needs as a multiline or even as a multinational. Our industrial clients branching out abroad want to have the same quality of cover as in their home markets and therefore ask for the sort of global cover which can be sustained only by substantial amounts of capital. 
Plans to expand into Allfinanz/Bancassurance call for a deep pocket and therefore can be thwarted by lack of capital. Equally, co-operative ventures and partnerships require a certain equality among the partners in quality, size and prospects.

\subsection{Allinanz/Bancassurance}

At the beginning of the eighties, service companies started a wave of mergers and integrations under the banner of "Bancassurance" or "Allfinanz". In this process, certain areas of banking and insurance started to overlap. "Allfinanz" entails developing a comprehensive and integrated concept to cover all the financial and security needs of a client under one roof, if possible over his or her whole life. The financial services (r)evolution instigated these changes. This was a US innovation which introduced an all singing, all dancing financial services provider. Just think of Allstate and Sears Roebuck : goods, travel, banking and insurance, all in one magic roundabout.

In Europe, the retail element of goods has not been at the forefront despite the recent foray of Marks \& Spencer into the life assurance market in the UK. However, in Europe, an ever increasing number of life assurance policies are being sold by banks through their branch network. According to computations of Citiversicherung, the life premium income generated through banks in Europe has reached DM $100 \mathrm{bn}$. Throughout Europe, banks thus have rapidly gained an important position as a life distribution channel. Within the last ten years, credit institutions have increased their share of the life market threefold. One out of every four life assurance policies now is being sold either directly or indirectly through a bank. In Spain, some 70 percent of total business is being transacted via banks. In the UK and France banks have been selling life assurance for over thirty years and have some 40 percent of the market.

Examples of the very successful co-operation between banks and insurance companies are to be found especially in France and the UK. For example in France, Predica, a subsidiary of Crédit Agricole, was founded in 1985 and in five years jumped to the second place in the French life assurance market.

There have been other examples of links between insurance and banking such as ING, UAP and Trustee Savings Bank. The latter, TSB, has evolved over decades. They were successful as they were the first in the UK to adopt such a strategy. They had the right customer base and the correct image; and they learned the art of cross selling by trial and error, refining their methods as they went along. ING is a recent development. The strategy of the Group, according to a recent Geneva Association paper, is on the one hand to diversify and then to allow the business units to specialize, focusing on the retail and small commercial markets. The Group is being reorganized away from product specialization to a new organization according to distribution channels.

One has to be aware, however, that there is no homogeneity in the financial services market and that there is a multitude of products and market segments. Different clients require appropriate financial services via a made-to-measure distribution channel. The Allfinanz concepts have great difficulties in meeting these requirements : banking staff rarely posses the necessary expertise to explain to a customer the complexities of an insurance product to the same degree that they could explain a banking product. On the other hand, insurance salesmen face the same difficulties when selling international pension funds. 
Another strategy of bringing a bundle of services to a client is via alliances and cooperations.

\subsection{Alliances and co-operations}

There is great potential if financial services providers decide to enter co-operation agreements and form alliances. These range from agreements between insurance companies to alliances between banks and insurance companies. An example is specialist providers, such as legal protection insurers or assistance companies, who can offer add-ons to more standard products. These add-on providers thèrefore could have agreements with a great number of other insurance companies. The add-ons, like in the motor industry, are out-sourced.

A limited number of products and a low cost sales channel are the key success factors of the strategy. They enable cost savings in the distribution process by selling via the bank counter and clearly separated distribution channels which are adapted to the specific needs of the customer.

The cost savings for the insurer are derived from the higher productivity of salesmen who have leads from the bank. On the other hand, the bank receives a commission to subsidize its branches.

\subsection{The customer's viewpoint}

We thus far have discussed the multiline or niche question from the point of view of the seller. The more important question has been left out, namely what does the customer want? The evidence suggests that, speaking for the Western European markets, he has an increasing need for asset protection and investment products. At the same time, there has been a polarization in the demand for such financial services. On the one hand, price sensitivity and profitability awareness are increasing for standard products. On the other hand, the demand for quality products which require advice and are therefore expensive is also increasing.

After the new EU directive takes effect on July 1, 1994, there will be an abundance of new non-standard products. For these, the customer will require more advice. This offers excellent opportunities for companies which are able to provide such services. From the client's point of view, the most promising financial services provider is one who concentrates on the activities he understands best, as the customer will benefit from that know-how. If the productivity of the distributing channel is increased, the resulting benefits could be passed on to the customer.

Thus, the strategy of forming alliances and co-operations is for the benefit of both the insurance company and the client. Therefore, this strategy will be very successful in the future.

\subsection{Conclusion}

Even though companies have to adapt to their changing environment, there is no universal answer to the multiline or niche question. Small niche carriers, whether they are specialized in certain products, regions or customer segments, will survive in increasingly acrimonious competition if they possess specialized knowledge or cost advantages. Mediumsized companies will face the greatest challenges, as they generally do not benefit from such 
advantages. Strong multinational players will benefit from the globalization strategy of their clients, a more balanced risk profile and economies of scale. Whatever strategy is adopted by companies, there is one immutable constraint: the insurance industry relies on the trust of its customers. It has to honor its commitments, and its strategy ultimately must be geared to increasing the security underlying each and every policy.

\section{Insurance as a long term proposition}

Insurance, like banking, relies on trust - on the ability to meet obligations as and when they fall due. It is of paramount importance for our industry to maintain an unbroken chain of security. The stronger players increasingly will make their customers aware of the need for security: indeed, the large brokers know only too well the potential for large law suits if they fail to take security into account when advising their clients. Let us therefore examine where the threats to financial stability could occur and how to deal with them.

\subsection{Insurance is by nature a long term proposition}

Insurance is a contractual promise to indemnify loss or damage, perhaps over many years (e.g., life assurance, health insurance, liability and some engineering contracts).

Insurance products are based on the law of large numbers and have been priced to spread the result evenly over many years, sometimes decades or longer (e.g., motor insurance for the law of averages).

Insurance funds have to be built up over years to absorb new risks (e.g., life assurance and pensions, insurance pools).

Despite the long term nature of insurance, insurance buyers, insurance providers, investors in insurance, governments and the legal system often take a short term view, to the detriment of the industry and its customers.

\subsection{Insurance buyers will benefit by taking a long term view}

Buyers who are prepared to enter into a longer term relationship with their insurers generally will benefit from fidelity discounts and can expect the service to improve, especially in the case of claim. If they change carriers frequently (e.g., in the UK motor market lapse rates of 25 percent are not unusual), the insurer has to recoup the additional costs somewhat, either by rate increases or from shareholders.

If buyers only look to the cheapest insurance company and not to the one which provides the best security, they risk facing the same fate as the policyholders of failed insurance companies. Even in countries where funds have been established to protect policyholders, the terms are restrictive, as not all policyholders are covered; and even if they are covered, they usually suffer additional administrative complications and delay. This also affects professional buyers of reinsurance who have been damaged by insolvent reinsurers.

In order to minimize the risk, clients should take a long term view. They ought to seek a longer term relationship with their insurers who then can return to the policyholders the administrative benefits they thus gain. Customers also should be prepared to pay for security. The rule "caveat emptor" (buyer beware) applies. In the long run, it pays to be protected adequately.

\subsection{Insurers will benefit by taking a long term view}

The entire insurance industry will benefit if it can convey to its customers that its 
members will be there when the time comes to pay the claim. Insurance companies therefore have to evolve long term strategies. If they reduce rates in the hope of gaining market share, they are adopting a strategy which is not sustainable and is diffcult to reverse. The prime examples of where these strategies were used and failed were in the German fire markets, the UK personal lines market and the international excess of loss markets. The cutting of rates by one company leads to retaliation by other companies, creating an unstoppable momentum. After a time, the companies realize the error of their strategies, restore rates and for a short while lose market share until all other companies follow suit. In some cases, the knee jerk reaction to past losses is too brutal. Rates are increased so dramatically that clients prefer to self insure or create mutuals, and new competitions are attracted to the market.

Furthermore, underwriters have to make sure that they understand the risks they are carrying. Some will underwrite risks without sufficient knowledge of their exposure or of the proper rate. This weakness particularly affects companies entering new market segments in the hope of a quick kill. Some markets are built around a follow-the-leader concept. The innocent capacity which follows does so at its own peril.

Insurers also have to make sure that they do not underreserve. This problem has had more effect on liability insurers than on life insurers. The latter are generally under stricter supervision as to their rates and reserving methodology. In the short term, underreserving, like rate cutting, gives the insurer a short term advantage. However, in the longer term, the customer or the investor in the insurance company gets short changed.

Some insurers have sought to expand by hostile acquisition, buying other insurance companies at a too high price when these companies are underreserved. We all know that insurance is a complex, long term business. Published statutory information rarely gives a complete picture. Comprehensive audits and reserve testing are required. Hostile acquisitions generally are decided at short notice with insufficient information and with illusory synergies being held out as the reward. Friendly take-overs on the other hand take a long time. The search for the ideal partner is a time consuming affair and the parties have to get to know each other and exchange information.

The consequence of rate cutting, underreserving and hostile acquisitions is that either the policyholder or the shareholder in the insurance company gets hurt. Sometimes the insurance company becomes insolvent or it lets the subsidiary go into liquidation. The consequences are not limited to the one company as other companies follow the herd instinct and also jump over the cliff. As a consequence, confidence in the industry is undermined.

\subsection{Investors also benefit by taking a long term view}

Many investors driven by short term factors misunderstand the nature of insurance as a long term proposition. For example, investors in the UK thought that three year accounting meant a three year exposure. For many, it is turning out to be a very expensive mistake with long term consequences.

Another unhealthy phenomenon is the present influx of insurers in Bermuda. The withdrawal of capacity from that market is likely to be equally dramatic. This misunderstanding frequently leads to increased share prices of insurance companies following a major disaster. Investors hope or assume that insurers can push up the insurance rates immediately to recoup their losses. 
The consequence for individual investors is that a short term attitude can have financially disastrous consequences. These investors in turn put pressure on insurance companies and syndicates who they feel are forced to take short term measures such as boosting their market share and cash flow despite the long term adverse consequences.

Investors in insurance have to take a long term view. Short term thinking puts undue pressure on insurers, to the detriment of the long term results of the industry.

\subsection{Governments and legal systems should take a long term view}

If, as pointed out in the first section, the insurance industry is to take on the burden of controlling pollution through the pricing mechanism of the market and making the polluter pay through his insurance policy, the industry must be given the opportunity to build up the necessary funds for future claims.

If the insurance industry is to take over the role of providing for people in their old age, governments must make life and pensions insurance attractive for consumers and not consider a life policy as a possible source of taxation. At the same time, legislators and judges have to consider the effects on insurance when enacting or interpreting new laws. Generous indemnities will make it more difficult to determine the right insurance premium and the correct reserves.

All the points mentioned above show that insurance is a long term proposition by its very nature. Neglecting it leads to disadvantages not only for the carriers, but also for clients and investors.

\section{General summary/key findings}

- The needs of customers keep changing at an ever increasing pace, entailing new opportunities and challenges for insurers.

- There is no generally valid answer to the question of whether to be multiline or niche. The strategy of an insurer depends on many conditions, such as financial strength, comparative competitive advantages and market structure. There are strong arguments for the prediction that strong multinational players and competitive small niche players will survive in the long run.

- Insurance is a long term proposition by its very nature. Buyers, suppliers, investors and governments alike will benefit by adopting a long term approach. 